\title{
THE DIAGNOSTIC VALUE OF C-REACTIVE PROTEIN IN INFECTED TOTAL HIP ARTHROPLASTIES
}

\author{
L. SANZÉN, Å.S. CARLSSON
}

From Lund University, Sweden

\begin{abstract}
In 50 patients with non-infected total hip arthroplasties (THA), 233 C-reactive protein (CRP) values were obtained over a three-year period. Six of these 50 patients occasionally had CRP values of over $20 \mathrm{mg} / \mathrm{l}$. The erythrocyte sedimentation rate (ESR) and CRP concentration were measured in 23 patients with deep infections of THA before revision. In 11 patients the infections were caused by coagulase-negative staphylococci. CRP exceeded $20 \mathrm{mg} / \mathrm{l}$ in 18 patients and the ESR was more than $30 \mathrm{~mm} / \mathrm{hr}$ in 14 . In only one infected patient were both CRP and ESR below these levels. All of 33 patients with non-septic loosening had CRP $<20 \mathrm{mg} / \mathrm{l}$ and ESR $<30 \mathrm{~mm} / \mathrm{hr}$ before revision. C-reactive protein seems to be a valuable supplement to the ESR in the monitoring of infection after THA.
\end{abstract}

C-reactive protein (CRP) is an acute-phase protein normally present only in trace amounts in plasma. At the onset of an acute inflammatory condition, CRP concentration begins to rise within a few hours and reaches values up to a thousand times normal within 24 hours (Carr 1983). After a total hip replacement, CRP concentrations reach 200 to $400 \mathrm{mg} / \mathrm{l}$ within 48 hours and return to normal in about three weeks (Aalto et al 1984; Shih, Wu and Yang 1987). Since the normal CRP is not measurable with standard laboratory techniques, it is often reported as $<5$ or $<10 \mathrm{mg} / \mathrm{l}$.

CRP has been shown to be more sensitive than the erythrocyte sedimentation rate (ESR) in the identification of children with bacteraemia (Bennish, Beem and Ormiste 1984) and exacerbations of chronic osteomyelitis (Hedström 1983). Since 1981, CRP and the ESR have been measured at our department before total hip arthroplasties (THA) and at postoperative reviews. Our aim was to investigate the usefulness of CRP in the detection of deep infections after total hip arthroplasties.

\section{PATIENTS AND METHODS}

Between 1981 and 1987 we revised a total hip arthroplasty because of deep infection in 14 men and nine women without rheumatoid arthritis (median age 74 years, range 40 to 80 ). The infections were confirmed by multiple

L. Sanzén, MD,

A.. S. Carlsson, MD,

Department of Orthopaedics, Lund University, Malmö General Hospital, S-214 01 Malmö, Sweden.

Correspondence should be sent to Dr L. Sanzén.

(C) 1989 British Editorial Society of Bone and Joint Surgery 0301-620X/89/4109\$2.00

J Bone Joint Surg [Br] 1989;71-B :638-41 positive bacteriological cultures of biopsy specimens from the bone-cement interface obtained during revision surgery. Five patients had acute onset of symptoms suggesting a haematogenous infection. In six patients who had had their primary operation done in our unit, CRP had been measured several times between operation and revision. In the other 17 patients, CRP was measured just before revision. Thirteen of the 23 patients had been referred from other centres.

Two groups of patients were controls. Group 1 consisted of 50 patients with an uneventful primary THA for osteoarthritis (median age at operation 68 years, range 39 to 84 ) and who had been clinically and radiographically followed up over at least three years. One pre-operative and several postoperative CRP values had been measured. Group 2 consisted of 35 patients revised over two years for mechanical loosening of their THA (median age at revision 69 years, range 42 to 79 ), all of whom had negative cultures at operation. CRP values were estimated before revision. We excluded one patient with chronic hepatitis and one whose CRP was not measured before revision.

Antibiotics were not given from six weeks before revision until the tissue biopsy had been done, except in the patients with haematogenous infections. CRP values were measured by electroimmunoassay (Laurell 1972), and values of under $10 \mathrm{mg} / \mathrm{l}$ were judged normal. The ESR in the first hour was measured by the Westergren method (1926).

\section{RESULTS}

Table I shows CRP and ESR values immediately before revision in all infected patients, together with the results of cultures at operation. Before revision, CRP levels and 


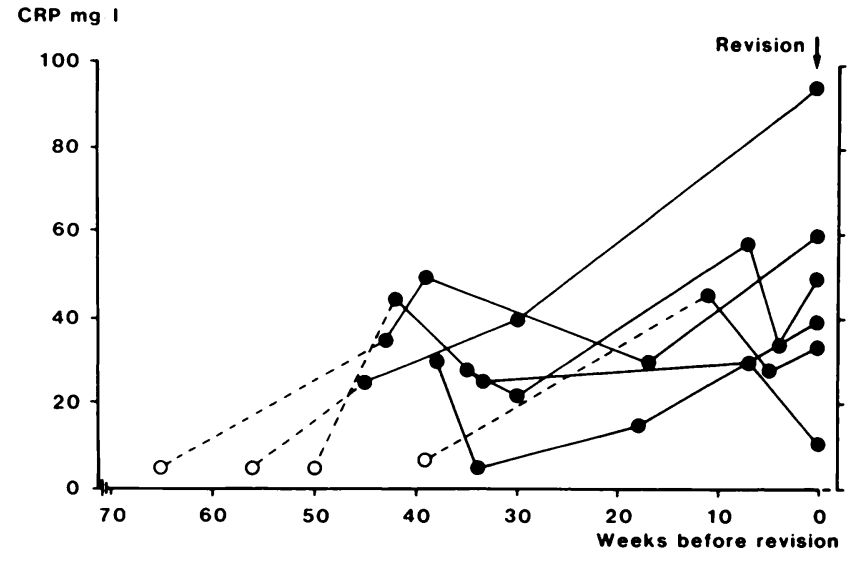

Fig. 1

CRP levels before revision operations in six patients with deep infection of a total hip arthroplasty. The open circles in four cases represent the CRP value before the primary operation. the ESR were significantly higher in the infected patients than in those with mechanical loosening $(p<0.001$ for both, Mann-Whitney rank-sum test).

In five of the 23 infected patients, CRP did not exceed $20 \mathrm{mg} / \mathrm{l}$ but four of them had an ESR of at least $30 \mathrm{~mm} / \mathrm{hr}$. Figure 1 shows CRP values in six patients operated on and followed-up at our unit from 11 up to 45 weeks before revision. In two of these six patients the primary THA was performed before 1981 and therefore we do not have their pre-operative CRP values. The other four patients had a normal CRP before surgery.

In the group 1 controls (uncomplicated THA) CRP and the ESR had been measured a total of 233 times between three months and four years after operation (or three to seven times per patient). Thirty patients had normal values (below $10 \mathrm{mg} / \mathrm{l}$ ). In the other 20 patients 30 of 99 values were $10 \mathrm{mg} / \mathrm{l}$ or over, but only seven values in six patients exceeded $20 \mathrm{mg} / \mathrm{l}$. In these six

Table I. ESR, CRP and bacteriology in 23 non-rheumatoid patients before revision of an infected total hip arthroplasty

\begin{tabular}{|c|c|c|c|c|c|}
\hline Patient & $\begin{array}{l}\text { Age }(y r) \text { at } \\
\text { revision }\end{array}$ & Sex & $\begin{array}{l}\text { ESR } \\
(\mathrm{mm} / \mathrm{h})\end{array}$ & $\begin{array}{l}\text { CRP } \\
(\mathbf{m g} / \mathbf{l})\end{array}$ & Bacteriology \\
\hline 1 & 40 & $\mathbf{M}$ & 5 & 24 & Coagulase-negative staphylococcus \\
\hline 2 & 61 & $\mathbf{M}$ & 58 & 75 & Coagulase-negative staphylococcus \\
\hline 3 & 62 & $\mathbf{M}$ & 48 & 95 & Coagulase-negative staphylococcus \\
\hline $4^{*}$ & 66 & $\mathrm{~F}$ & 58 & 26 & Coagulase-negative staphylococcus \\
\hline 5 & 70 & F & 41 & 40 & Coagulase-negative staphylococcus \\
\hline 6 & 73 & $\mathbf{M}$ & 28 & 34 & Coagulase-negative staphylococcus \\
\hline 7 & 74 & $\mathbf{F}$ & 60 & 12 & Coagulase-negative staphylococcus \\
\hline 8 & 77 & $\mathbf{M}$ & 25 & 10 & Coagulase-negative staphylococcus \\
\hline 9 & 78 & $\mathbf{F}$ & 10 & 60 & Coagulase-negative staphylococcus \\
\hline 10 & 82 & $\mathbf{M}$ & 50 & 10 & Coagulase-negative staphylococcus \\
\hline 11 & 74 & $\mathbf{M}$ & 67 & 150 & Staphylococcus aureus \\
\hline $12^{*}$ & 69 & $\mathbf{M}$ & 112 & 182 & $\beta$-streptococcus group $\mathrm{G}$ \\
\hline $13^{*}$ & 76 & $\mathrm{~F}$ & 13 & 325 & $\beta$-streptococcus group $\mathrm{G}$ \\
\hline $14^{*}$ & 80 & $\mathbf{M}$ & 100 & 155 & $\beta$-streptococcus group $\mathrm{G}$ \\
\hline 15 & 69 & $\mathrm{~F}$ & 120 & 22 & Enterococcus \\
\hline 16 & 79 & $\mathrm{~F}$ & 59 & 50 & Enterococcus \\
\hline 17 & 75 & $\mathbf{M}$ & 60 & 60 & Pepto-streptococcus \\
\hline 18 & 59 & $\mathrm{~F}$ & 25 & 35 & Escherichia coli \\
\hline $19^{*}$ & 74 & $\mathbf{M}$ & 19 & 50 & Escherichia coli \\
\hline 20 & 77 & $\mathbf{M}$ & 56 & 45 & Escherichia coli \\
\hline 21 & 74 & $\mathbf{M}$ & 40 & 19 & Diphtheroids \\
\hline 22 & 66 & $\mathbf{M}$ & 30 & 20 & $\begin{array}{l}\text { Peptococcus magnus } \\
\text { Propionibacterium acne }\end{array}$ \\
\hline 23 & 75 & $\mathrm{~F}$ & 27 & 60 & $\begin{array}{l}\text { Coagulase-negative staphylococcus } \\
\text { Propionibacterium acne }\end{array}$ \\
\hline
\end{tabular}

* haematogenous infection 
patients the operated hips were symptom-free and there was a probable explanation for the raised CRP concentration in five. The two highest values (50 and $115 \mathrm{mg} / \mathrm{l})$ occurred in a patient with diverticular disease of the colon. This patient also had the highest ESR $(63 \mathrm{~mm} / \mathrm{hr})$ in group 1 and was the only control with an ESR above $30 \mathrm{~mm} / \mathrm{hr}$ and a CRP above $20 \mathrm{mg} / \mathrm{l}$ at the same time. The mean ESR for each patient was calculated; the means ranged from 5 to $42 \mathrm{~mm} / \mathrm{hr}$ (median $17 \mathrm{~mm} / \mathrm{hr}$ ). Sixteen of the $233 \mathrm{ESR}$ values exceeded $30 \mathrm{~mm} / \mathrm{hr}$, and they occurred in 11 patients.

The 33 controls in group 2 (revised for mechanical loosening) had a median ESR of $10 \mathrm{~mm} / \mathrm{hr}$ (range 1 to 28) before revision. In 24 the CRP was below $10 \mathrm{mg} / \mathrm{l}$, in five it was $10 \mathrm{mg} / \mathrm{l}$, and in the remaining four it was 15 , 15,17 and $19 \mathrm{mg} / \mathrm{l}$.

\section{DISCUSSION}

The possibility of deep infection after total hip replacement can be monitored by measurement of the ESR. Since the normal range of ESR is wide, values from healthy and infected patients can overlap, thus leading to difficulties in interpretation (Carlsson 1978). If we had chosen $30 \mathrm{~mm} / \mathrm{hr}$ as the upper normal limit, 16 of the 233 postoperative ESR values would have been abnormally high in control group 1 . On the other hand nine out of 23 infected patients had an ESR not exceeding $30 \mathrm{~mm} / \mathrm{hr}$ immediately before revision surgery.

CRP is also unspecific and is increased in a number of infective and traumatic conditions. However, in contrast to the ESR the normal CRP value is very low (Kindmark 1972) and persistent elevation of CRP in healthy individuals is uncommon (Palosuo et al 1986). In our controls, followed up for several years, temporary slight increases of CRP were common, probably reflecting the fact that even trivial maladies of short duration cause an increase in CRP. Nevertheless, deep infection should be suspected in otherwise healthy individuals with several increased CRP values and pain after THA.

Shih et al (1987) have reported THA revisions in 28 patients, of whom five had a deep infection. In these five patients the CRP values before revision were 89 to $135 \mathrm{mg} / \mathrm{l}$ and the ESR was 16 to $62 \mathrm{~mm} / \mathrm{hr}$. The infections were caused by Staphylococcus aureus, Streptococcus group D, Enterococcus, Pseudomonas aeruginosa, and a yeast-like organism. Many of our patients had lower CRP and ESR values and the infecting organisms were mainly different from those found by Shih et al.

We were able to identify six patients in whom CRP had been measured on several occasions after the primary THA and who had symptoms of a deep infection, confirmed at revision. All six patients had a delayed infection in which symptoms gradually became more pronounced; infection was then suspected and finally confirmed. Unlike patients without complications, in whom CRP returns to normal in about three weeks
(Aalto et al 1984), these patients had a slight to moderate increase in CRP after the operation. One patient had a normal CRP on one occasion. In none of the six patients were antibiotics prescribed, which if given might have suppressed the inflammatory response and thus have lowered the CRP.

CRP is raised in patients with rheumatoid arthritis and correlates roughly with the extent and activity of the disease (Amos et al 1977). The use of CRP to diagnose prosthetic infections in such patients would be unreliable, especially in infection causing only a slight or moderate increase in CRP and ESR. We have had very few bacteriologically confirmed THA infections in rheumatoid arthritis and have therefore not reported such patients here. However, a pronounced increase above the pre-operative value should be noted and may add support to a clinical suspicion of deep infection.

Before revision surgery the presence of a deep infection is not always obvious to the surgeon. We encountered two such cases (patients 7 and 9 in Table I) in which several cultures were positive. On the other hand, a clinically suspected infection is not always confirmed by culture at revision. Such false-negative cultures might be attributable to ineffective culturing techniques or pre-operative antibiotic treatment. We did not include such cases for this report, but one example was a women who had both normal and increased CRP values (up to $30 \mathrm{mg} / \mathrm{l}$ ) over two years after a primary THA. She never became pain-free postoperatively and the radiographs showed signs of loosening of both components. At revision bacteriological cultures were negative. This patient may have had an infection of very low virulence, difficult to verify microbiologically and causing only slight and intermittent tissue damage (reflected by an occasionally increased CRP). Gristina and Costerton (1985) have described microscopic findings of bacteria adhering to plastic surfaces of hip prostheses which could not be grown in tissue culture.

In our study the pre-revision CRP values were significantly higher in infected than in non-infected patients. However, high CRP values were not present in all infected patients. We could not establish the frequency of normal CRP values in the presence of a deep prosthetic infection, but CRP concentration seems to be normal in some infections with bacteria of low virulence, whereas high values are generally seen in infections with Staphylococcus aureus and $\beta$-streptococci.

It is noteworthy that the ESR and CRP were not raised simultaneously in all our patients with deep infections. Some patients had normal ESR and an increased CRP, and others had a high ESR and low CRP. The largest difference - CRP $325 \mathrm{mg} / 1$ and ESR $13 \mathrm{~mm} / \mathrm{hr}$ - was probably due to the fact that the tests were done soon after the onset of a haematogenous infection, so that the ESR had not had time to rise. Even a moderate increase in the ESR or CRP can be consistent with a deep infection, as seen in some of our patients. In 
such patients measurement of both ESR and CRP before the primary operation is very useful. Since CRP seems to react somewhat differently from the ESR, both methods are useful; they supplement each other in the monitoring of complications after THA.

Financial support was obtained from the Herman Järnhardt, Alfred Österlund and Greta and Johan Kock Foundations.

No benefits in any form have been received or will be received from a commercial party related directly or indirectly to the subject of this article.

\section{REFERENCES}

Aalto K, Österman K, Peltola H, Räsänen J. Changes in erythrocyte sedimentation rate and $\mathrm{C}$-reactive protein after total hip arthroplasty. Clin Orthop 1984:184:118-20.

Amos RS, Constable TJ, Crockson RA, Crockson AP, McConkey B. Rheumatoid arthritis: relation of serum C-reactive protein and erythrocyte sedimentation rates to radiographic changes. $\mathrm{Br} \mathrm{Med}$ $J$ 1977.195-7.
Bennish M, Beem MO, Ormiste V. C-reactive protein and zeta sedimentation ratio as indicators of bacteremia in pediatric patients. J Pediatr 1984:104:729-32.

Carr WP. Acute-phase proteins. Clin Rheum Dis 1983:9:227-39.

Carlsson AS. Erythrocyte sedimentation rate in infected and noninfected total hip arthroplasties. Acta Orthop Scand 1978;49:287. 90.

Gristina AG, Costerton JW. Bacterial adherence to biomaterials and tissue: the significance of its role in clinical sepsis. $J$ Bone Joint Surg [ Am] 1985;67-A :264-73.

Hedström SA. Immunoassay of acute phase reactants and latex-CRP as activity tests in chronic staphylococcal osteomyelitis. Scand J Infect Dis 1983;15:161-5.

Kindmark C-O. The concentration of C-reactive protein in sera from healthy individuals. Scand J Clin Lab Incest 1972:29:407-11.

Laurell CB. Electroimmuno assay. Scand $J$ Clin Lab Incest 1972:29:[Suppl 124]:21-37

Palosuo T, Husman T, Koistinen J, Aho K. C-reactive protein in population samples. Acta Med Scand 1986:220:175-9.

Shih L-Y, Wu J-J, Yang D-J. Erythrocyte sedimentation rate and Creactive protein values in patients with total hip arthroplasty. Clin Orthop 1987:225:238-46.

Westergren A. Technique of red cell sedimentation reaction. Am Rer Tuberc 1926:14:94-101. 